\title{
A NEW SPECIES OF TRISSOPELOPIA KIEFFER, 1923 (DIPTERA, CHIRONOMIDAE, TANYPODINAE, PENTANEURINI) FROM INDIA
}

\author{
N. Hazra \& P. K. Chaudhuri*
}

\begin{abstract}
N. Hazra \& P. K. Chaudhuri. 2010. A new species of Trissopelopia Kieffer, 1923 (Diptera, Chironomidae, Tanypodinae, Pentaneurini) from India. Graellsia, 66(1): 39-45.

The pupae and adults of Trissopelopia bifurcata sp. $\mathbf{n}$. are recorded and described from the Darjeeling Himalayas of India. The genus is recorded for the first time in India. A new key to the world species of Trissopelopia is also included.
\end{abstract}

Key-words: Trissopelopia bifurcata; new species; pupa; imago; Chironomidae; India.

\section{RESUMEN}

N. Hazra \& P. K. Chaudhuri. 2010. Nueva especie de Trissopelopia Kieffer, 1923 (Diptera, Chironomidae, Tanypodinae, Pentaneurini) de la India. Graellsia, 66(1): 39-45 (en inglés).

Se describen las pupas y los adultos de Trissopelopia bifurcata sp. n. procedentes del Darjeeling Himalayas (India). Es la primera cita del género en la India. Se proporciona, asimismo, una nueva clave mundial de las especies de Trissopelopia.

Key-words: Trissopelopia bifurcata; new species; pupa; imago; Chironomidae; India.

\section{Introduction}

In course of our investigation of the dipteran fauna in the Darjeeling Himalayas, three pupae came to our attention in a stream near Mirik lake, which on rearing resulted in one male and two females of the tanypod genus Trissopelopia Kieffer, 1923 of the family Chironomidae. The genus is related to Pentaneura Philippi, 1865 and Pentaneurella Fittkau \& Murray, 1983. The males of Trissopelopia lack distinct lyrate tibial spurs and setae on the pos- terior border of tergite IX while that of Pentaneura the terminal spur of gonostylus is very much larger. The absence of distinct scutal tubercle further distinguishes adults of Trissopelopia from those of Pentaneuralla.

The adult of the genus is characterized by medium to large size, distal flagellomere $3.0 \mathrm{x}$ as long as broad, two rows of 9-10 lateral antepronotals, acrostichals merged with dorsocentrals extending up to prescutellar area; wing with dense macrotrichia, C slightly produced and ending little before $\mathrm{M}_{1+2}$, 
$\mathrm{MCu}$ just beyond $\mathrm{FCu}$, anal lobe well developed; tibial spurs with 10-14 lateral teeth, outer hind spur much smaller than the inner one with 4 lateral teeth, hind tibial comb indistinct; anal point conical, gonocoxite robust 1.5-2.00 $\mathrm{x}$ as long as broad with short anterior and long posterior setae, gonostylus slender, curved with a small terminal seta.

The pupa is known by medium to large size, pale to dark brown exuviae, thorax 3-4 $\mathrm{x}$ as long as broad and interconnected at the base, outer spinules forming scales, horn sac tubular with swollen base occupying about $1 / 2$ lumen width, plastron plate more or less oval, corona $2 \mathrm{x}$ as long as plastron plate and 0.5 $\mathrm{x}$ horn length, thoracic comb anteriorly rugose, thoracic membrane smooth, thoracic setae filamentous or simple, $\mathrm{Dc}_{1 .}$ and $\mathrm{Sa}$ filamentous and of equal length, $\mathrm{Dc}_{2}$ simple more or less $0.5 \mathrm{x}$ as long as $\mathrm{Dc}_{1}$. Tergite I with little pigmented scar, shagreen in short and transverse groups or in arched rows, I-VII more or less granulate at posterior margin, pedes spurii A at the posterior corners of II-VI, D and V setae short and filamentous, L seta filamentous more like the longest D seta, VII with 4 LS setae at the distal half and VIII with 5 LS setae. Anal lobe little convex 3.0 $\mathrm{x}$ as long as broad, toothed and genital sac 0.5.

Before the present study, only 7 species represented the genus around the world (01Afrotropical, 01 Nearctic, 02 Oriental and 03 Palaearctic) without any record from India (Cheng \& Wang, 2005).

\section{Material and methods}

The pupae procured from a slow moving stream near Mirik Lake were subjected to rearing in the laboratory. The fresh imagines and pupal exuviae were processed and mounted on micro-slides after Hazra et al. (2002). In describing the imagine and pupa, terminologies and usages of Sæther (1980) were followed.

Measurements are in micrometers $(\mu \mathrm{m})$ except the total length of the body and the wing which are in millimeters $(\mathrm{mm})$. The average values are before and the ranges are suffixed by "n" and the number of specimens examined is within parentheses

Types are presently kept at the Entomology Laboratory of the Department of Zoology, The University of Burdwan, Burdwan and will be deposited in the National Zoological Collections (NZC), Kolkata and The Museum of Natural History (BMNH), London in due time.

\section{Trissopelopia bifurcata sp. $\mathbf{n}$.}

(Figs. 1-3)

Type Material. Holotype $\sigma^{\top}$ adult (reared) and pupa (Type no. B.U. Ent. 241), West Bengal: Mirik (Lat. 26²60'N, Long.

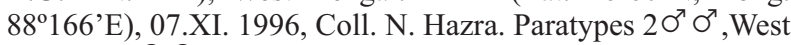
Bengal; 2 우 우 with pupal exuvia, data same as holotype; $20^{\top} \sigma^{\top}$, West Bengal: Darjeeling (Lat. $27^{\circ} 02^{\prime} \mathrm{N}$, Long. $88^{\circ} 10^{\prime} \mathrm{E}$ ), 05.V.2005, Coll. U. Majumdar.

DiAgNOSTIC CHARACTERS. The male imago may be separated from others by: i) unique marking on TII-VII along the lateral margins, ii) 11 flagellomeres with AR1.75, iii) smaller spur on hind tibia with 4 teeth, iv) 37-40 squamal setae and v) gonocoxite 1.48 times as long as broad. The pupa is recognized by: i) oval plastron plate occupying 0.35 length of the horn, ii) apex of thoracic horn bifurcated with a deflexed swelling below the plastron plate, iii) Thr 2.9, iv) $\mathrm{LS}_{1}$ seta on segment VII at 0.33 segment length and v) ALR 2.53.

\section{DESCRIPTION}

Male. Total length $5.1(5.1-5.2, \mathrm{n}=3) \mathrm{mm}$, wing length $3.6 \mathrm{~mm}$, total length/wing length 1.42 ; wing length/length of profemur 2.54 .

Table 1.- Lengths and proportion of leg segments.

Tabla 1.- Longitud y proporciones de los segmentos de las patas.

\begin{tabular}{|c|c|c|c|c|c|c|c|c|c|c|c|}
\hline & $\mathrm{Fe}$ & $\mathrm{Ti}$ & $\mathrm{ta}_{1}$ & $\mathrm{ta}_{2}$ & $\mathrm{ta}_{3}$ & $\mathrm{ta}_{4}$ & $\mathrm{ta}_{5}$ & LR & BV & sv & BR \\
\hline$p_{1}$ & 1415 & 2165 & 2158 & 860 & 703 & 389 & 148 & 0.99 & 1.9 & 2.16 & 3.9 \\
\hline$p_{2}$ & 1610 & 2017 & 1277 & 453 & 379 & 259 & 139 & 0.63 & 4 & 4.55 & 2.2 \\
\hline$p_{3}$ & 1286 & 2164 & 1610 & 944 & 666 & 427 & 148 & 0.74 & 2.3 & 2.87 & 2.9 \\
\hline
\end{tabular}



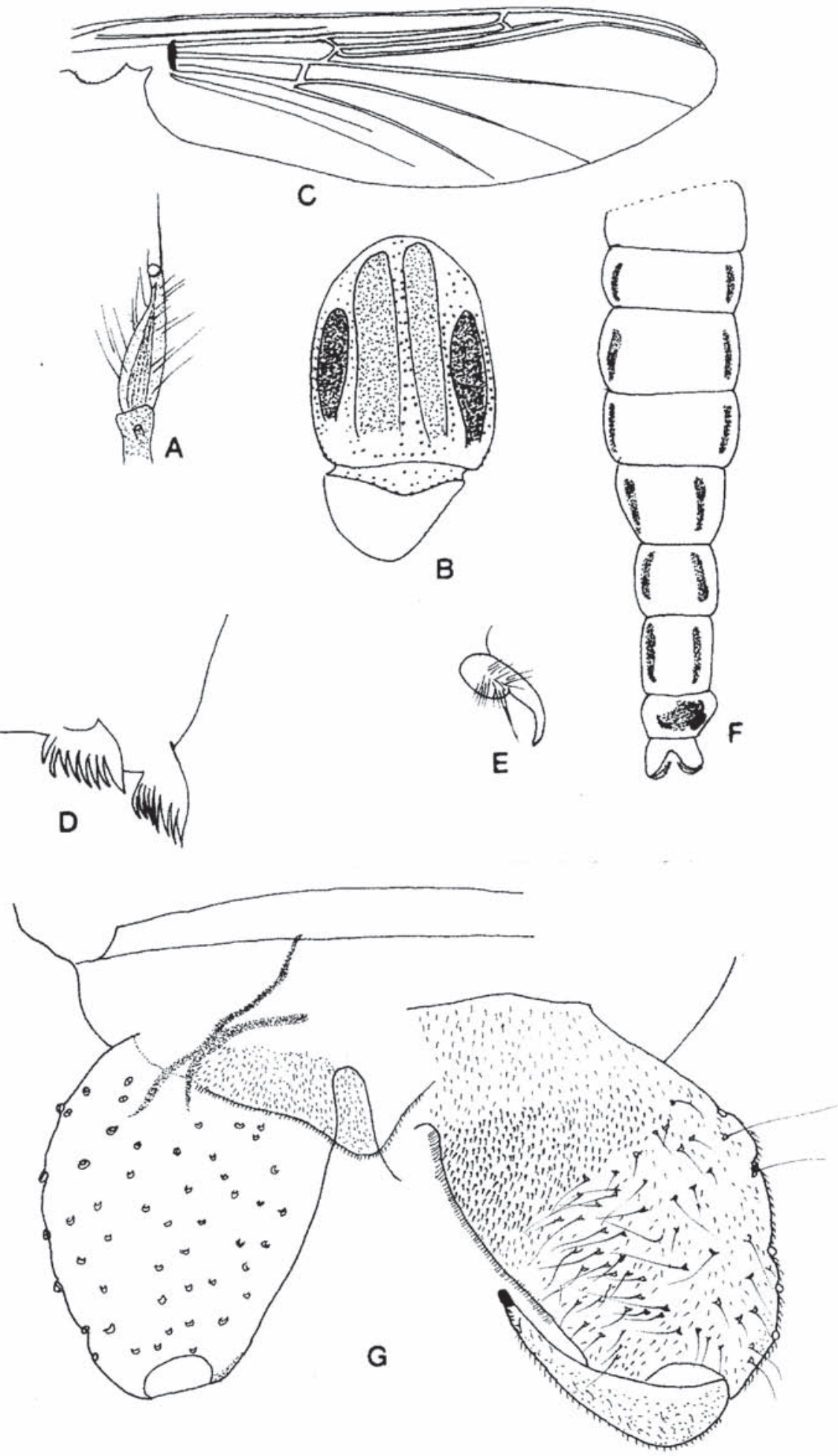

Fig. 1.- Adult male of Trissopelopia bifurcata sp. n. A) antenna, B) thorax, C) wing, D) midtibia, E) claw, F) abdomen and G) hypopygium.

Fig. 1.- Macho adulto de Trissopelopia bifurcata sp. n. A) antena, B) tórax, C) ala, D) tibia de la segunda pata, E) uña, F) abdomen y G) hipopigio. 

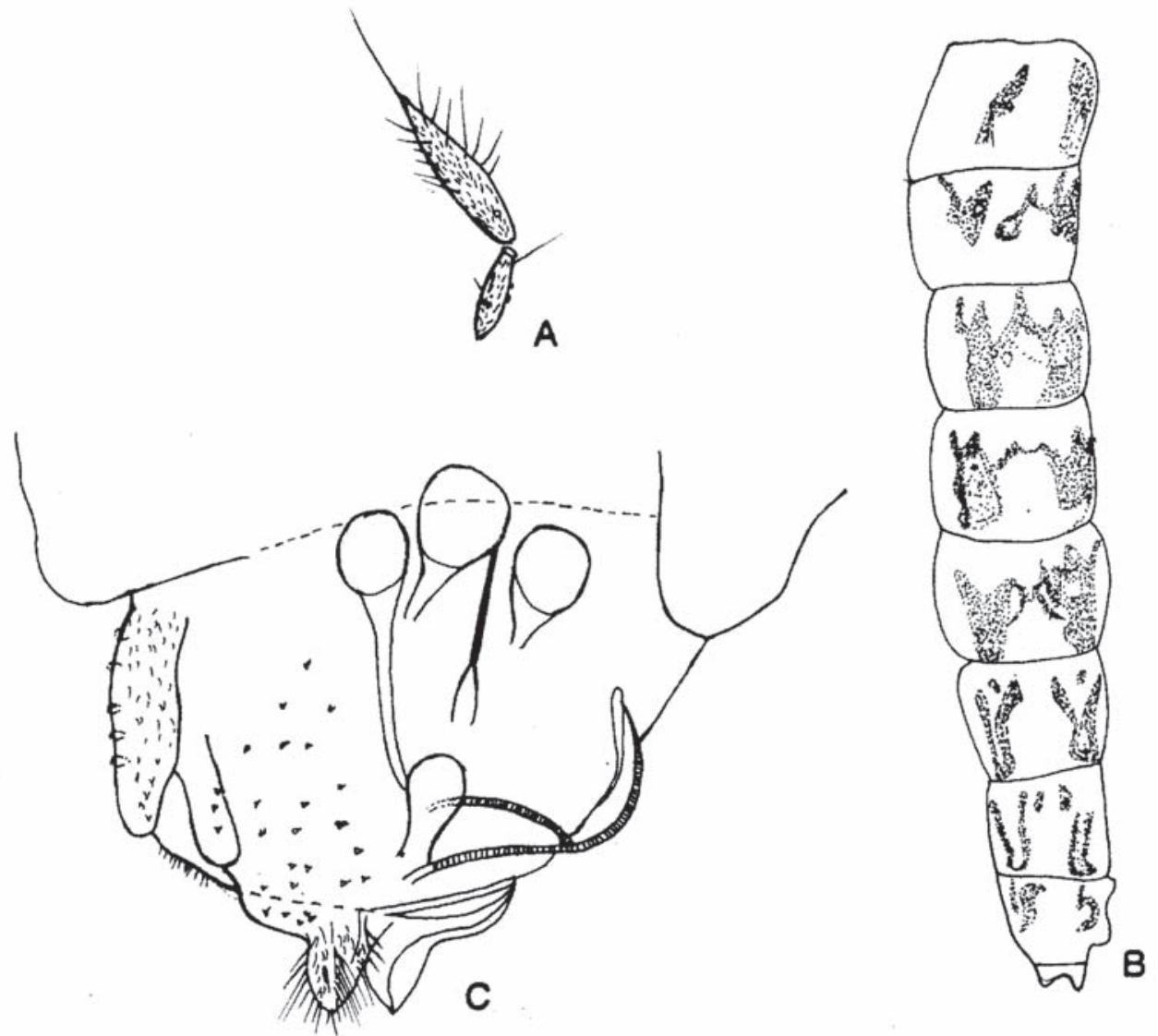

Fig. 2.- Adult female of Trissopelopia bifurcata sp. n. A) antenna, B) abdomen and C) genitalia.

Fig. 2.- Hembra adulta de Trissopelopia bifurcata sp. n. A) antena, B) abdomen y C) genitalia.

Head. Eyes bare with dorsomedian extension 160. Antenna with 11 flagellomeres, flagellomere $\mathrm{X}$ (Fig. 1A) and flagellomeres XI 855 and 90 long respectively, ratio between flagellomere $\mathrm{X} /$ flagellomere XI 9.5. Temporal setae 21 uniserial (7 IV, 5 0V, 9 Po). Corona with 8 setae, clypeus with 23 setae. Lengths of palpomeres (I-V): 45, 135, 180 , 240, 360, segment II with distal tuft of 12 long setae, length being 106. Tentorium 210 long, 35 wide, cibarial pump 495. AR 1.75, CA $0.5, \mathrm{CP}$ 0.67 .

Thorax (Fig. 1B). Thorax brown with anepisternum II and two darkly pigmented lateral vittae; antepronotum weakly developed with 5-6 antepronotals, large weakly sclerotized humeral pit, arcrostichals 34 biserial, dorsocentrals 17 uniserial, prealars 18, supra-alars 3 and scutellars 21 .
Wing (Fig. 1C). Membrane with numerous macrotrichia in cells and without pigment marks. Brachiolum with 2 setae, costa slightly produced beyond $\mathrm{R}_{4+5}$ ending little before $\mathrm{M}_{1+2}$, costal extension $60(60-61, n=3)$, squama with 37-40 setae. Anal lobe evenly rounded. CR 0.94, VR 0.67.

Legs (Table 1). Spur of fore tibia, 10, mid tibia (Fig. 1D) 7 and 9 and hind tibia with 8 and 4 lateral teeth. Claw (Fig. 1E) strongly curved and pointed.

Abdomen (Fig. 1F). Pale yellow in color. TIIVII each with dark brown narrow stripes along the lateral margin; VIII with a dark more or less rounded mark at the middle.

Hypopygium (Fig. 1G). Anal point broad, blunt $37(37-38, n=3)$ long. Gonocoxite length $210(210-$ $211, n=3)$, breadth $142(141-142, n=4)$ with 1.48 times as long as broad with strong setae at base; 


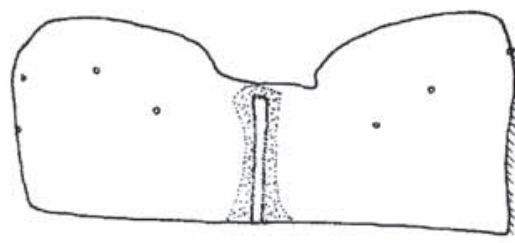

B
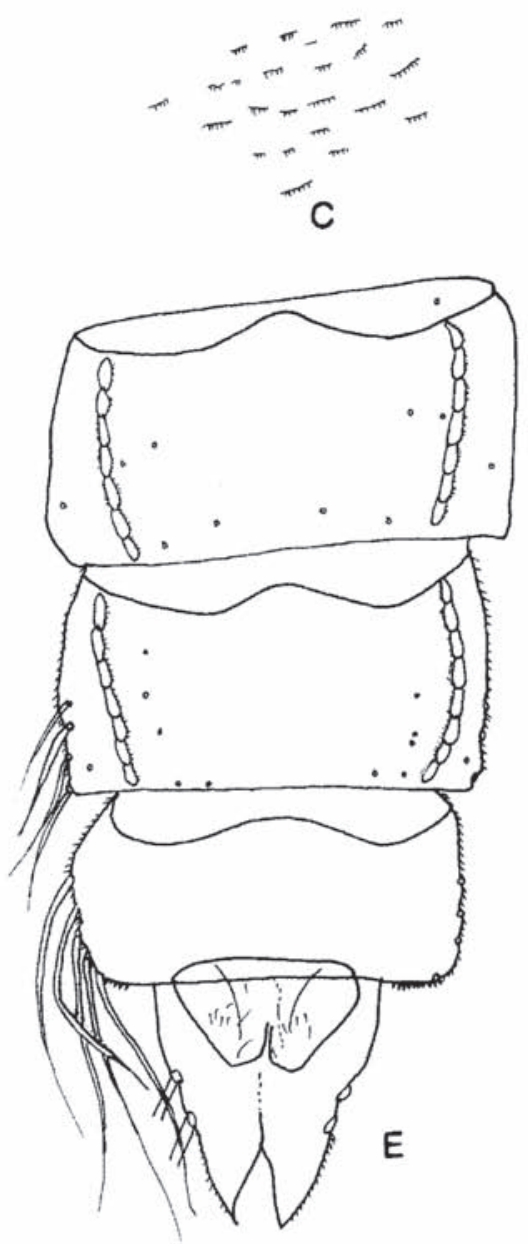

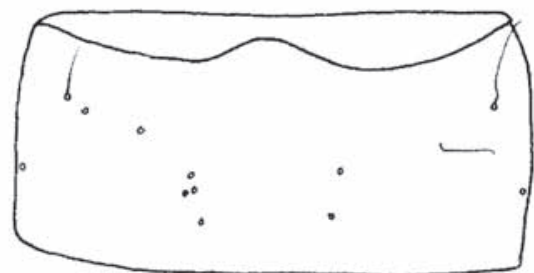

D

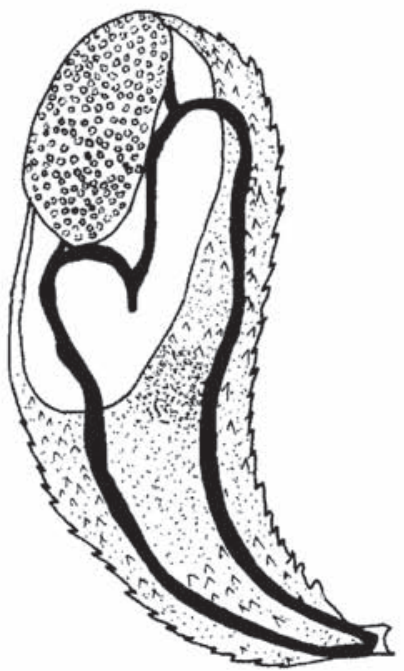

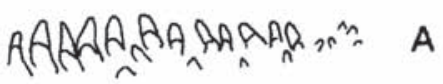

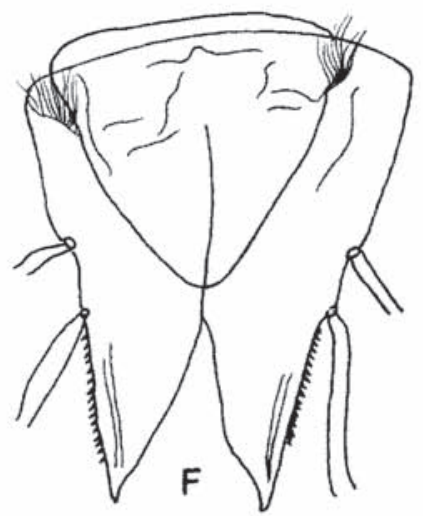

Fig. 3.- Pupa of Trissopelopia bifurcata sp. n. A) thoracic horn and comb, B) tergite I showing scar, C) shagreen, D) segment IV showing setal pattern, E) segments VI-VIII and anal lobe, and F) anal lobe and genital sac.

Fig. 3.- Pupa de Trissopelopia bifurcata sp. n. A) cuerno y peine torácicos, B) terguito I con la señal, C) microescultura, D) segmento IV con la quetotaxia, E) segmentos VI-VIII y lóbulo anal y F) lóbulo anal y saco genital. 
gonostylus length $126(n=3)$, simple and slightly curved, basal width 33, terminal spur 7 long; phallapodeme 104 long; sternapodeme 74 long. HR 1.67; HV 4.04.

Female. Similar to male with usual sexual differences. Antenna (Fig. 2A) 12 segmented, AR 0.19. TI-VII each with dark brown markings (Fig. 2B). Genitalia (Fig. 2C). Gonocoxite length $46(n=2), 7$ with 5-6 setae. Cercus 57 long with numerous setae. Notum $170(n=2)$ long. Seminal capsules $84(n=2)$ in diameter, brown and 3 in number. Gonapophysis VIII 114 long, projecting a little towards the opposite lobe. Vaginal opening blunt and oval.

Pupa. Brown in color. Total length of exuviae 6.1 (5.9-6.1, $\mathrm{n}=3)$. T II-VII with dark brown field at the antero-median border.

Cephalothorax. Thoracic horn (Fig. 3A) 390 (390-392, n= 3) long, expanded at the apex, breadth $135(\mathrm{n}=3)$; Thr 2.89, plastron plate oval 134 (133$134, n=3)$ long and $88(88-89, n=3)$ wide occupying $0.34(0.34-0.35, n=3)$ length of horn, corona occupying $0.56(0.56-0.57, \mathrm{n}=3)$ length of horn, $1.76(n=3) x$ as long as plastron plate, respiratory horn bifurcated with a deflexed swelling below the plastron plate, basal lobe oval, height 33, thoracic comb (Fig. 3A) of 14 large and 5-9 small tubercles.

Abdomen. Scar on T I (Fig. 3B) 263-315 long, II-VII with groups of dense shagreen (Fig. 3C) in slightly arched rows, segment IV with setal pattern as in the figure 3D, VII with 4 LS setae at $0.3-0.33$, $0.36-0.38,0.43-0.45$ and $0.5-0.53$ of segment length, VIII with 5 LS setae (Fig. 3E) at 0.17-0.19, $0.24-0.26,0.30-0.32,0.36-0.38$ and $0.41-0.42$ of segment length. Anal lobe (Fig. 3F) 570 x 450 with 15 outer spinules. Anal macrosetae at 0.41 and 0.54 of length of anal lobe. G/F 0.57, ALR 2.5-2.7.

Etymology. The name "bifurcata" derives from the bifurcated thoracic horn of the pupa.

Discussion. The new species appears identical with the European species Trissopelopia longimana (Stæger, 1839) and T. ogemawi Roback, 1971 in pupal characters like, thoracic horn, plastron plate, corona, Thr and ALR, and characters of adult male like, anal point, LR of male imagine, but the location of anterior LS seta of segment VII of the pupa AR, smaller spur and number of lateral teeth of hind tibia are quite different from those of the above species. It bears affinities with T. montivaga Harrison, 1978 in respect to AR and anal point but differs in LR and gonostylus. The species Trissopelopia lanceolata
Cheng \& Wang, 2005 and Trissopelopia dimorpha Cheng \& Wang, 2005 from China and T. oyabetrispinosa Sasa, Kawai \& Ueno, 1988 of Japan differ markedly from the present species in abdominal coloration, number of antennal flagellomeres and AR. This justifies its consideration as a new member of Trissopelopia Kieffer from India.

ECOLOGY. The larvae are cold stenothermic and polyoxybiontic found in littoral and shallow montane streams and lakes of the Himalayas of Darjeeling, India.

\section{Key to the world species of Trissopelopia}

1. Tarsomere I of fore legs with six large lanceolate sensilla chaetica T. lanceolata

- Tarsomere I of forelegs without sensilla chaetica ........ 2

2. Antenna with 11 or 12 flagellomeres ............................ 3

- Antenna with 14 flagellomeres ........................................ 4

3. Antenna with 11 flagellomeres, $A R>1.75$ T. bifurcata sp. $\mathrm{n}$.

- Antenna with 11-12 flagellomeres, AR $<1.0$ T. dimorpha

4. Hind tibial comb with three comb setae T. oyabetrispinosa

- Hind tibia without comb setae ........................................ 5

5. Mid $\mathrm{Ta}_{2}<\mathrm{Ta}_{3}, \mathrm{LR}_{1}<\mathrm{LR}_{2}=\mathrm{LR}_{3} \ldots \ldots \ldots \ldots \ldots . . . . . . . . . .1$. ogemawi

- $\quad$ Mid $\mathrm{Ta}_{2}>\mathrm{Ta}_{3}, \mathrm{LR}_{1}=\mathrm{LR}_{2}<\mathrm{LR}_{3}$ 6

6. TII-VIII and hypopygium mostly dark. LRII 0.56; smallest spur on Ti III with 7 lateral teeth

T. montivaga

- TII-VI/VII with anterior transverse dark bands; hypopygium pale; LRII 0.62-0.64; smallest spur on Ti with 4 lateral teeth 7

7. Wing length $3.6-4.0 \mathrm{~mm}$; deep reddish-brown species .. T. Iongimana

- Wing length 3.0-3.4 mm; generally pale yellowish species T. flavida

\section{Acknowledgements}

We are thankful to the Ministry of Environment \& Forests, Government of India for financial assistance and to the Heads of the Department of Zoology, University of Burdwan, Burdwan and Darjeeling Government College, Darjeeling for laboratory facilities.

\section{References}

Cheng, M. \& Wang, X., 2005. Two new species of Trissopelopia Kieffer from China with emendation of the generic diagnosis and a key to the adult male 
Trissopelopia of the world (Diptera; Chironomidae: Tanypodiae). Entomological News, 116(1): 15-22.

Fittkau, E. J. \& Murray, D. A., 1983. Pentaneurella katterjokki, eine neue Gattung und Art der Tanypodinae (Dipt. Chironomidae). Nachrichtenblatt der Bayerischen Entomologen, 32: 57-63.

Harrison, A. D., 1978. New genera and species of Tanypodinae (Diptera: Chironomidae) from the Africa South of Sahara. Journal of the Entomological Society of South Africa, 41: 63-80.

Hazra, N., Saha, G. K. \& Chaudhuri, P. K., 2002. Records of Orthoclad species from the DarjeelingSikkim Himalayas of India (Diptera: Chironomidae), with notes on their ecology. Hydrobiologia, 474: 4155.

Kieffer, J. J., 1923. Chironomides de l'Afrique Equatoriale. III İme. Annales de la Société Entomologique de France, 92: 149-204.

Phillipi, R. A., 1865. Aufzählung der chilenischen Dipteren. Verhandlungen der Kaiserlich-Königlichen Zoologisch-Botanischen Gesellschaft in Wien, 15: 595-782.

Roback, S. S., 1971. The subfamily Tanypodinae in North America. The adults of the subfamily Tanypodinae (Pelopiinae) in North America (Diptera: Chironomidae). Monographs of the Academy of Natural Science of Philadelphia, 17: 1-410.

Sæther, O. A., 1980. Glossary of chironomid morphology, terminology (Diptera Chironomidae). Entomologica Scandinavica Supplement, 14: 1-51.
Sasa, M., Kawai, K. \& Ueno, R., 1988. Studies on the Chironomid midges of the Oyabe River, Toyama, Japan. Research Report of Toyama Prefectural Environmental Pollution Research Center: 26-85.

Stæger, R. C., 1839. Systematisk fortegnelse over de i Danmark hidtil fundne Diptera. Naturhistorisk Tidsskrift, 2: 549-600.
Recibido, 4-I-2010 Aceptado, 2-VI-.2010 Publicado, 30-VI-2010 